\title{
RELATIVIZAÇÃO DO PRINCÍPIO DA SOBERANIA DOS VEREDICTOS
}

RELIABILITY OF THE PRINCIPLE OF THE SOVEREIGNTY OF THE VERDICTES

\section{Lauro Mens de Mello ${ }^{1}$}

ISSUE DOI: $10.21207 / 1983.4225 .342$

\section{RESUMO}

O texto versa sobre a possibilidade de se relativizar o disposto no artigo 593, $\S 3^{\circ}$ do Código de Processo Penal para se permitir mais de uma vez o julgamento nas hipóteses tratadas nesse dispositivo. De início, far-se-á uma análise histórica sobre a origem do Tribunal do Júri. Em seguida, analisar-se-á a soberania dos veredictos e sua amplitude, demonstrando que não cabe a submissão a novo julgamento quando os jurados optam por uma das teses possíveis e ressaltando a posição tradicional, segundo a qual, em havendo anulação pelo artigo 593, III, " $d$ ", é impossível anulação novamente pela mesma alínea, qualquer que tenha sido a decisão tomada. Tal interpretação, denominada declarativa, em verdade não é uma interpretação, mas uma ilusão, razão pela qual deve ser usada a zetética para que a norma seja interpretada de forma mais aberta e em consonância com princípios constitucionais, como ampla defesa, duplo grau de jurisdição, celeridade processual e inafastabilidade do controle jurisdicional; assim, tais princípios, condensam e direcionam a interpretação da norma e permitem que no caso concreto se faça a justiça material. Diante

${ }^{1}$ Possui graduação em Direito pela Universidade de São Paulo (1989) e mestrado em Direito (Franca) pela Universidade Estadual Paulista Júlio de Mesquita Filho (2000). Atualmente é Professor Titular da Faculdade de Direito de Franca e Juiz de Direito da Tribunal de Justica do Estado de Sao Paulo. Tem experiência na área de Direito, com ênfase em Direito Público. 
dessas premissas, propõe-se que se relativize ou mitigue a soberania dos veredictos para que em caso de segunda decisão dos jurados manifestamente contrária a prova dos autos e que condene o acusado, o tribunal absolva-o, impedindo, destarte, que se eternize o julgamento.

Palavras-chave: Júri. Soberania dos veredictos. Zetética. Relativização. Justiça material.

\section{ABSTRACT}

The text is about the possibility of relativizing the provisions of article 593, paragraph 3 of the Code of Criminal Procedure to allow more than once the judgment in the cases dealt with in this provision. At the outset, a historical analysis will be made of the origin of the Jury's Court. Next, the sovereignty of the verdicts and their amplitude will be analyzed, demonstrating that it is not possible to submit to a new trial when the jurors choose one of the possible theses and emphasizing the traditional position, according to which, in case of annulment by article 593, III, "d", it is impossible to cancel again by the same point, whatever the decision has been taken. Such an interpretation, called declarative, is not really an interpretation, but an illusion, which is why zetética must be used in order for the norm to be interpreted more openly and in line with constitutional principles, such as broad defense, double jurisdiction, Procedural celerity and inafasability of jurisdictional control; Thus, these principles condense and direct the interpretation of the norm and allow in the concrete case to do the material justice. In view of these premises, it is proposed to relativize or mitigate the sovereignty of the verdicts so that in the event of a second decision of the jurors manifestly contrary to the evidence in the case and that condemns the accused, the court absolves it, preventing it from becoming eternal The judgement.

Keywords: Jury. Sovereignty of verdicts. Zetética. Relativization. Material justice.

\section{INTRODUÇÃO}

A questão que se busca analisar versa acerca dos limites da soberania dos veredictos e a possibilidade de alteração da decisão dos jura- 
dos em face do disposto no artigo 593, $\S 3^{\circ}$ (in fine), do Código de Processo Penal, que pró́be ao Tribunal de Apelação apreciar apelação pelo mesmo motivo uma segunda vez.

Tal matéria mostra-se relevante visto a possibilidade de serem realizados dois julgamentos pelo Tribunal do Júri e, nos dois casos, a solução ser manifestamente contrária à prova dos autos.

Nesse caso, deve-se ter a soberania dos veredictos como um princípio absoluto, mesmo em face do status libertatis e do princípio da dignidade humana, levando ao cárcere pessoa que, segundo as provas, não se mostra culpada; ou, em sentido contrário, relativizá-lo e fazer uma interpretação conforme a Constituição da norma infraconstitucional.

\section{ORIGEM E FINALIDADE DO TRIBUNAL DO JÚRI}

O momento em que se deu a origem histórica do Tribunal do Júri mostra-se bastante controvertido, sendo difícil apontar o instante exato de seu surgimento.

Rui Barbosa ${ }^{2}$ ao tratar da matéria afirma que

se o Júri, de que se encontra a prefiguração longínqua nos judices romanos ("Le jugement par de véritables jurés". Guérin: "Étude Sur Les Droits et Libert. Du Citoyen aux Et. Unis. Bulletin de la Soc. De Lelisl. Comp. 1892, p. 320 n - Lesser: Jury System, c. III), se não nos dikastas gregos, e nos centini comitês dos primitivos germanos, imortalizados por Tácito (Tácito: De Situ ac Populis Germanioe, XII), autorizando historiadores e entusiastas seus a gabarem-no de medir o curso da civilização ("The development of de jury may justly be said to measure the march of civilization". Lesser: "The Historical Development of the Jury System", New York, 1894, p. 14 - “... the jury thus gained ground with advancing civilization, gradually superseding the more ancient and barbarous customs...".

2 BARBOSA, Rui. O Júri sob todos os aspectos. Rio de Janeiro: Editora Nacional de Direito, 1950. p.7. 
Macclacklan: Eng. Cycl. III, 26 - "The jury system is both the cause and proof of civilization and liberty". Cox: Three Decades of Federal Legislation, p. 604), se o Júri, associado, nas investigação das sua origens histórias, ora aos teutões, ora aos eslavos, já aos normandos, já aos dinamarqueses (Ellis Stevens: "Sources of the Constitution of the United States", p. 233-4. - Franqueville: "Le Système Judiciaire de la Grande Bretagne", I, p. 490-92), recebeu os primeiros traços da sua forma definitiva no solo britânico, depois da conquista normanda, sob Henrique II, extinguindo-se na França, de onde fora transplantado nos seus mais grosseiros rudimentos com as Capitulares (Stubbs: "The Constitutional History of England", v. I, p. 612-15), na média idade inglesa é que se revestiu a imagem, sob que a era moderna o adotou.

Arthur Pinto da Rocha ${ }^{3}$, ao contrário, indica que a origem reside na antiga legislação mosaica.

Tais orientações apenas indicam a dificuldade de se fixar o momento histórico, embora seja razoavelmente tranquilo que nos moldes atuais remonta à época da Common Law, segunda metade do século XII, como afirma John Gilissen ${ }^{4}$

Porém, o ponto mais importante para a obtenção de solução para a questão acerca da intangibilidade da soberania dos veredictos, reside no fato de que ele nasceu com a finalidade de combater o julgamento realizado com base tão somente no arbítrio do líder da sociedade, servindo de instrumento de garantia para a liberdade individual.

\section{SOBERANIA DOS VEREDICTOS}

${ }^{3}$ BARBOSA, Rui. O Júri e sua evolução. Rio de Janeiro: Leite Ribeiro \& Maurillo, 1919. p. 8-9.

${ }^{4}$ GILISSEN, John. Introdução histórica do direito. 3.ed. Lisboa: Fundação Calouste Gulbenkian, 2001. p. 214. 
Em sede de julgamentos pelo Tribunal do Júri, adota-se o princípio constitucional da soberania dos veredictos, nos termos do artigo $5^{\circ}$, XXXVIII, $c$, da Constituição Federal.

No mesmo sentido, o Código de Processo Penal, no seu artigo 593 , III, $d$, c.c. $\S 3^{\circ}$, prevê que a análise do fato realizado pelos jurados é soberana, salvo se manifestamente contrária à prova dos autos.

Damásio Evangelista de Jesus ${ }^{5}$ afirma que

é pacífico que o advérbio "manifestamente" (III, d) dá bem a ideia de que só se admite seja o julgamento anulado quando a decisão do Conselho de Sentença é arbitrária, porque se dissocia integralmente da prova dos autos. E não contraia esta a decisão que, com supedâneo nos elementos de convicção deles constante, opte por uma das versões apresentadas.

No mesmo sentido Júlio Fabbrini Mirabete ${ }^{6}$ ao afirmar que

o art. 593, inciso III, prevê a apelação do Tribunal do Júri quando "for a decisão dos jurados manifestamente contrária à prova dos autos" (alínea d). Trata-se de hipótese em que se fere justamente o mérito da causa, em que o "error in judicando" é reconhecido somente quando a decisão é arbitrária, porque se dissocia integralmente da prova dos autos, é contrária manifestamente à verdade apurada no processo e representa uma distorção da função judicante do Conselho de Sentença. Assim, não é qualquer dissonância entre $o$ veredicto $e$ os elementos de convicção colhidos na instrução que autoriza a cassação do julgamento. Unicamente a decisão dos jurados que nenhum arrimo encontra na prova dos autos é que pode ser invalidada.

5 JESUS, Damásio Evangelista de. Código de Processo Penal Anotado. 15.ed. São Paulo: Saraiva, 1998. p.422.

${ }^{6}$ MIRABETE, Júlio Fabbrini. Processo Penal. São Paulo: Atlas, 1991. p.612-613. 
Hermínio Alberto Marques Porto7 destaca que "o entendimento do conceito de soberania reaparece com seus efeitos após o julgamento pelo Tribunal do Júri, por ocasião do exame de apelação buscando a rescisão, pelo mérito, do decidido pelos jurados; ao Tribunal do Júri cabe proferir decisão, então não manifestamente contrária à prova, que encontre amparo em contingente menor de provas em conflito; e decisões com tal amparo, que não prevaleceriam, em regra, quando proferidas por Juiz singular, são mantidas porque excepcional a marginalização das decisões dos jurados, o entendimento do conceito de soberania dá atenção a seus limites, agora, então sem caráter ampliativo e indevido".

Fernando da Costa Tourinho Filho ${ }^{8}$, tratando do tema relata que "não permitiram, em nenhum caso, pudesse a instância superior reexaminar a causa e proferir a decisão adequada. Autorizaram ao Tribunal ad quem corrigir as distorções, guando o erro partir do Presidente do Júri, jamais quanto ao pronunciamento do Conselho de Sentença".

Finalmente, como bem afirmou Uadi Lammêgo Bulos', que "não foi sem razão que o constituinte incluiu a soberania dos veredictos no catálogo das liberdades públicas da Constituição. Nem sempre julgamentos provenientes de juízes togados conseguem auscultar as transformações do fato social cambiante. Elegendo-se pessoas leigas para decidirem a respeito dos problemas relacionados ao jus libertatis é garantir o sentimento do povo, porque o formalismo da lei nem sempre acompanha o fato e a vontade popular. Quantas vezes o legislador emite comandos normativos gerais e abstratos divorciados da realidade fática? Erigindo-se a soberania dos veredictos ao patamar constitucional, o tribunal leigo poderá considerar e sopesar critérios não auferidos pela lei. Daí a sua justificação".

\footnotetext{
7 PORTO, Hermínio Alberto Marques. Júri: procedimento e aspectos do julgamento. Questionários. 5.ed. São Paulo: Revista dos Tribunais, 1989. p.33.

8 TOURINHO FILHO, Fernando da Costa. Processo Penal. 12.ed. São Paulo: Saraiva, 1998. v.4. p.55-56.

9 BULOS, Uadi Lammêgo. Constituição Federal Anotada. São Paulo: Saraiva, 2000. p.203.
} 
Ou seja, "optando, dentro do seu livre convencimento, pela versão que lhe pareça mais razoável, o Júri não se afastará do conjunto probatório. Poderá a orientação ser criticável, poderá até achar-se em conflito com a prova, mas, desde que se trate de decisão do Júri, só na hipótese de um pronunciamento arbitrário, dissociado integralmente do apurado, insustentável, caberá a reforma" ${ }^{10}$.

Assim, "a decisão do Júri, que com supedâneo nos elementos constantes dos autos, opta por uma das versões apresentadas, não pode ser anulada sob alegação de ser contrária à prova dos autos, pois tal procedimento só se justifica quando a decisão dos jurados é arbitrária, totalmente dissociada do conjunto probatório" ${ }^{11}$.

Como visto a decisão do Tribunal do Júri, desde que escorada em prova produzida em juízo é válida, não sendo possível ao Tribunal ad quem valorar o acerto dessa decisão.

Nesse sentido, afirma Guilherme de Souza Nucci ${ }^{12}$ que "não cabe a anulação, quando os jurados optam por uma das correntes de interpretação da prova possíveis de surgir".

Apenas existe a possibilidade de, no caso de decisão manifestamente contrária à prova dos autos, anular-se a decisão para que novo julgamento seja realizado.

Tal postura indica, não só ser o princípio da soberania dos veredictos relativo, mas também a preocupação da realização da Justiça material.

\section{DA RELATIVIZAÇÃO DA SOBERANIA DOS VEREDICTOS}

A grande questão ocorre na hipótese de ser realizado um julgamento pelo Tribunal do Júri, com condenação do réu manifestamente

\footnotetext{
${ }^{10}$ TJSP - RT 398/102.

${ }^{11}$ TJSP - rel. Andrade Cavalcanti - RT 626/290.

${ }^{12}$ NUCCI, Guilherme de Souza. Código de Processo Penal Comentado. 11.ed. São Paulo: Revista dos Tribunais, 2012. p.1032.
} 
contrária à prova dos autos, pela segunda vez. Nesse caso seria inviável nova anulação.

Guilherme de Souza Nucci ${ }^{13}$ ao tratar da matéria afirma que "é razoável a proibição de haver recurso contra veredicto popular, por duas vezes, com base na mesma motivação, evitando-se prorrogação infindável de julgamentos".

Portanto, segundo a interpretação tradicional, lastreada no princípio da soberania dos veredictos, dever-se-ia anular o julgamento e determinar a realização de novo para que fosse reapreciada a decisão desvinculada da prova dos autos uma única vez.

Tal posicionamento pode ser definido como uma interpretação declarativa, que é a modalidade que implica em perfeita adequação da letra com o alcance da lei, sem qualquer "criação" por parte do aplicador de Direito.

Compreende a interpretação estrita e a interpretação lata - que são distintas da interpretação extensiva e da interpretação restritiva. Diferencia-se uma da outra pelo fato de que uma adota uma acepção mais extensa e outra menos extensa do vocábulo interpretado.

Ora, a interpretação declarativa, também chamada por Tércio Sampaio Ferraz Jr. de especificadora, é uma ilusão. E isto porque a norma, por ser composta de vocábulos da linguagem ordinária, traz em seu bojo dúvidas acerca do seu preciso alcance, além, é claro, das existentes ambiguidades da palavra.

Interessante ressaltar que para Carlos Maximiliano, a interpretação declarativa "não passa de exegese verbal, não é propriamente interpretação".

Sugere o autor que se esqueça a interpretação declarativa, pois ele apoiava-se no adágio, falso, in claris cessat interpretatio, e no brocardo de Direito Canônico, verba clara non admittunt interpretationem, neque voluntas conjecturam.

O grande problema da interpretação reside na vagueza, na ambiguidade advinda da língua natural, da textura aberta do direito. Por esse motivo, a interpretação, como instrumento para obtenção de justiça material, deve ter o caráter zetético.

13 NUCCI, Guilherme de Souza. Código de Processo Penal Comentado. 11.ed. São Paulo: Revista dos Tribunais, 2012. p. 1035. 
Zetética vem de zetein, que significa perquirir. Contrapõe-se à dogmática, que vem de dokein, que significa ensinar.

$\mathrm{Na}$ investigação zetética, ressalta-se o aspecto pergunta. Assim os conceitos básicos, as premissas, os princípios são tidos como elementos abertos, que podem sofrer críticas. Já na investigação dogmática, determinados elementos não permitem críticas ou discussões.

Destaca-se uma anedota histórica, onde

Sócrates estava sentado à porta de sua casa. Neste momento, passa um homem correndo e atrás dele um grupo de soldados. Um dos soldados então grita: 'agarre esse sujeito, ele é um ladrão!'. Ao que responde Sócrates: que você entende por 'ladrão'?.

Observa-se que para o soldado o significado de ladrão é uma questão resolvida, um ponto de partida para o seu problema, agarrá-lo. Já para Sócrates o significado ladrão é uma premissa vaga, que merece ser discutida e avaliada para, só depois, solucionada satisfatoriamente, passar-se à seguinte, agarrar o sujeito.

Em que pese o uso de determinados conceitos, como já definidos e aceitos no direito em geral e na interpretação em especial, deve sempre existir a possibilidade de discuti-los.

Aliás, pela característica do Direito, ser um fenômeno históricocultural, ou seja, que varia de acordo com o local e a época da sua aplicação, é necessária uma releitura do princípio da soberania dos veredictos.

Nesse sentido, citando a teoria tridimensional do direito de $\mathrm{Mi}$ guel Reale, expõe Christiano José de Andrade,

para a concepção tridimensional do direito este é um objeto cultural, ou seja, produto do pensar e do fazer do homem. Este, que é natureza e espírito, ser e dever ser, sujeito posto perante o objeto, projeta essa ambivalência nos autos e obras que instaura, isto é, confere sua dialeticidade ao mundo da cultura. E sendo o direito um objeto cultural, a natureza 
dialética da experiência jurídica decorre do ser mesmo do homem ${ }^{14}$.

Porém cabe ressaltar que a palavra dialética não é usada nos termos hegelianos ou marxistas. Deve ser entendida em novas bases, como afirma Miguel Reale, no sentido de que

sendo a realidade jurídica essencialmente temporal, cambiante e tridimensional, ainda mais uma composição necessária de estabilidade e movimento, somente uma dialética pluridimensional a ela se ajusta, tal como a dialética da complementaridade, que se desdobra em várias perspectivas, entre as quais as que correlacionam, necessária e reciprocamente, termos opostos ou distintos, numa relação de implicação ou de co-presença, ou então de funcionalidade entre contrários, entre meios e fins, entre forma e conteúdo, entre as partes e o todo ${ }^{15}$.

Como ressaltado, partindo de uma visão do conjunto, procura o intérprete entender a variação do mundo social, da dialética da complementariedade, em que os diversos fatores, fins e meios, juntam-se para solucionar os problemas e buscar a aplicação de uma justiça material, utilizando-se da elasticidade dos modelos jurídicos, sem abandonar critérios básicos de segurança.

Não se pode esquecer que a interpretação é sempre voltada para solução de problemas (questões em aberto que admitem mais de uma solução), ou conforme Christiano José de Andrade,

a interpretação está correlacionada com a aplicação da norma ao caso concreto. Logo, a aplicação do Direito, sua atuação, tem uma indispensável premissa na interpretação, que é dirigida uma finalidade normativa ou prática, tendente a

\footnotetext{
${ }^{14}$ ANDRADE, Christiano José de. Hermenêutica Jurídica no Brasil. São Paulo: Revista dos Tribunais, 1991. p.128.

${ }^{15}$ Ibidem.
} 
estabelecer um critério de decisão ou a uma máxima para a ação ${ }^{16}$.

Assim, não se pode assumir que uma interpretação, ainda que antiga e prestigiada, seja eterna e que sirva para a solução de todos os problemas jurídicos apresentados ao intérprete.

Logo, é inviável a aplicação pura e simples de um princípio ou regra, sem discussões, sem adequá-lo ao caso concreto, como se fosse uma verdade absoluta, uma vez que nos termos supra não há que se falar in claris cessat interpretatio, nem tampouco verba clara non admittunt interpretationem, neque voluntas conjecturam.

Em razão disso, discute-se o alcance do princípio da soberania dos veredictos juntamente com outros que podem ser aplicados no caso concreto, ou seja, a eventual ofensa ao princípio da ampla defesa, duplo grau de jurisdição, celeridade processual e inafastabilidade do controle jurisdicional.

Todos são princípios constitucionais, previstos no artigo $5^{\circ}$, incisos: XXXV; XXXVII, $c$; LV ${ }^{17}$; LXXVIII, da Constituição Federal, tidos por princípios materiais.

Para Karl Larenz "cuando remiten a un contenido intelectivo que conduce a una regulación, son principios "materiales", aunque les falte todavía el carácter formal de preposiciones jurídicas, representado por la conexión entre un "supuesto de hecho" y una "consecuencia juridica" ${ }^{18-19}$.

Os princípios funcionam influindo nas decisões acerca da determinada norma, regulando o conteúdo dessa norma por meio das decisões, sendo essa sua função positiva.

\footnotetext{
${ }^{16}$ ANDRADE, Christiano José de. Hermenêutica Jurídica no Brasil. São Paulo: Revista dos Tribunais, 1991. p. 108/109.

${ }^{17}$ Destaca-se que da disposição constitucional que garante a ampla defesa e meios e recurso a elas inerentes, decorrendo disto o princípio do duplo grau de jurisdição, nos termos do art. $5^{\circ}, \S 2^{\circ}$, da CF.

${ }^{18}$ Derecho justo : fundamentos de ética jurídica. Traducción Luis Diez-Picazo. 1. ed. Madrid: Editorial Civitas S.A., 1985. 33 p.

19 Tradução livre do autor: quando remetem a um conteúdo intelectivo que conduz a uma regulação, são princípios "materiais", ainda que lhes falte todavia o caráter formal de preposições jurídicas, representado pela conexão entre um "suposto fato" e uma "consequência jurídica”.
} 
Sob um aspecto negativo, os princípios iriam excluir os valores e normas que os afrontam.

Assim, o princípio passa a condensar-se em normas e decisões.

Para que isso ocorra, é necessário que se exerça um juízo de valor, juízo esse que nada mais é do que a materialização do princípio em face de uma norma, sendo aplicado de forma reiterada, possibilitando assim a materialização das decisões.

Dessa forma é possível concluir-se que o aspecto positivo teria sempre de ter certa dose de indeterminação, visto que o princípio iria se adequando conforme a aplicação da norma no tempo e no espaço.

Por tais motivos, não se pode afirmar que o princípio da soberania dos veredictos, materializado em várias decisões judiciais, tenha sempre um sentido e alcance determinados.

Já sob o aspecto negativo, essa dose de indeterminação, a rigor, não existiria, visto que seria mais simples verificar o choque de determinada norma com o juízo de valor acerca da materialização do princípio, do que o mecanismo de adequação desse juízo materializado em determinado caso.

Nesse sentido, afirma Karl Larenz que

la función positiva de los principios presenta una dosis de relativa indeterminación, que no existe en la función negativa, a menos que se trate de "casos límite. Por ello, la mayor parte de las veces es más fácil decir que esto o aquello es absolutamente injusto, inadecuado o desproporcionado, que decir que es precisamente lo justo, lo adecuado y lo proporcionado $^{20}$.

Robert Alexy, ${ }^{21}$ falando acerca do uso dos princípios, afirma que

\footnotetext{
${ }^{20}$ ANDRADE, Christiano José de. Hermenêutica Jurídica no Brasil. São Paulo: Revista dos Tribunais, 1991. p. 33.

${ }^{21}$ ALEXY, Robert. Conceito e validade do Direito. São Paulo: Martins Fontes, 2009. p. 85.
} 
a base do argumento dos princípios é constituída pela distinção entre regras e princípios. Regras são normas que, em caso de realização do ato, prescrevem uma consequência jurídica definitiva, ou seja, em caso de satisfação de determinados pressupostos, ordenam, proíbem ou permitem algo de forma definitiva. Por isso, podem ser designadas de forma simplificada como 'mandamentos definitivos'. Sua forma característica de aplicação é a subsunção. Por outro lado, os princípios são mandamentos de otimização. Como tais, são normas que ordenam que algo seja realizado em máxima medida relativamente às possibilidades reais $\mathrm{e}$ jurídicas. Isso significa que elas podem ser realizadas em diversos graus e que a medida exigida de sua realização depende não somente das possibilidades reais, mas também das possibilidades jurídicas. As possibilidades jurídicas da realização de um princípio são determinadas não só pelas regras, como também, essencialmente, por princípios opostos. Isso implica que os princípios sejam suscetíveis e carentes de ponderação. A ponderação é a forma característica da aplicação dos princípios.

A teoria de Alexy encontra eco na doutrina pátria, em que é citada para a solução de conflitos, entre normas e entre princípios. Nesse sentido, afirma Paulo Bonavides ${ }^{22}$

onde a distinção entre regras e princípios desponta com mais nitidez, no dizer de Alexy, é ao redor da colisão de princípios e do conflito de regras. Comum a colisões e conflitos é que duas normas, cada qual aplicada de per si, conduzem a resultados entre si incompatíveis, a saber, a dois juízos concretos e contraditórias de dever-ser jurídico. Distinguem-se, por conseguinte, no modo de solução do conflito. Afirma Alexy: 'um conflito entre regras somente pode ser resolvido se uma cláusula de exceção, que remova o conflito, for introduzida numa regra ou

${ }^{22}$ BONAVIDES, Paulo. Curso de Direito Constitucional - $6^{\text {a }}$ ed. - São Paulo: Malheiros $-1996-$ p. 251. 
pelo menos se uma das regras for declarada nula (ungülting)'. Juridicamente, segundo ele, uma norma vale ou não vale, e quando vale é aplicável a um caso, isto significa que suas consequências jurídicas também valem. Com uma colisão de princípios, tudo se passa de modo inteiramente distinto, conforme adverte Alexy. A colisão ocorre, p.ex., se algo é vedado por um princípio, mas permitido por outro, hipótese em que um dos princípios deve recuar. Isto, porém, não significa que o princípio do qual se abdica seja declarado nulo, nem que uma cláusula de exceção nele se introduza. Antes, que dizer - elucida Alexy - que, em determinadas circunstâncias, um princípio cede ao outro ou que, em situações distintas, a questão de prevalência se pode resolver de forma contrária. Com isso - afirma Alexy, cujos conceitos estamos literalmente reproduzindo - se quer dizer que os princípios têm um peso diferente nos casos concretos, e que o princípio de maior peso é o que prepondera. Já, os conflitos de regras assevera o eminente Jurista - se desenrolam na dimensão da validade, ao passo que a colisão de princípios, visto que somente princípios válidos podem colidir, transcorre fora da dimensão de validade, u seja, na dimensão do peso, isto é, do valor.

Com base no exposto acima, possível concluir-se, em relação ao caso concreto:

Inexiste qualquer direito absoluto, que não sofra variação em face do local, época de aplicação e circunstâncias do fato concreto;

Na aplicação de princípio não há que se falar em validade, mas em peso ou valor (no caso concreto), em que a aplicação é conformada por outros princípios;

Em um conflito aparente de princípios, possível a aplicação híbrida ou mitigada de um princípio pelo outro, sem que com isto diga-se que se negou a validade de qualquer um deles, sendo que se alterando o caso concreto, o princípio, que em determinada situação era preponderante, passa a ser secundário. 
Nesse sentido, possível afirmar-se que pelo princípio da soberania dos veredictos, quando lastreada segundo algum elemento de prova existente nos autos, não pode ser reapreciada pelo "Juiz Togado".

Porém, como a finalidade de toda norma é a consecução da Justiça material, entendida como de dar a cada um aquilo que lhe pertence na medida de seu merecimento e de acordo com as provas dos autos, não se pode sob alegação de adoção de um princípio, aceitar-se uma decisão flagrantemente injusta - na medida em que é frontalmente contrária à prova dos autos, exceção que a própria lei dá para o alcance das decisões dos jurados - cristalizando-se verdadeira teratologia jurídica, frontalmente contrária à finalidade do Direito.

Ressalta-se que a própria Lei Processual, ao concretizar em uma regra o princípio da soberania dos veredictos, constou que ele tem limite quando a prova dos autos é frontalmente contrária à decisão, como maneira de impedir realização de uma injustiça.

É certo que a própria Lei Processual só permite mais um julgamento quando a prova é contrária, sendo que, no caso dos jurados manterem a posição anterior, a mesma deve prevalecer.

Porém tal fato só se aplica quando for favorável ao réu, uma vez que a legislação, indiretamente, permite que os jurados absolvam o réu por motivos meta-jurídicos. Aliás, o próprio ordenamento, em determinadas situações, prevê anistia, graça, indulto etc., como forma de favorecer o status libertatis.

No entanto, em sentido contrário, ou seja, se a segunda decisão impuser uma condenação completamente divorciada do ordenamento ou dos fatos, não pode preponderar. E isso porque iria contra a própria função da aplicação Direito: fazer justiça no caso concreto.

Destarte, uma vez que todo princípio tem sua aplicação relativizada, salienta-se que os princípios podem ser aplicados em conjunto, com cada um complementando e condicionando o outro para obter-se a concretização.

Em outras palavras, possível que em determinada situação concreta exista a prevalência de um princípio, sem que com isso tenha-se por inexistente ou inaplicável o outro.

Nesse sentido, além dos autores já mencionados, é o ensinamento de Canotilho e Moreira ao afirmarem que "principios actuam conjuga- 
damente, complementando-se, condicionando-se e modificando-se em termos reciprocos ${ }^{\prime 23}$.

No mesmo sentido, Larenz para quem "os princípios recebem o seu peculiar conteúdo de sentido apenas no seu jogo concertado de complementação e restrição recíprocas "24.

O ponto a ser analisado para eleger-se um princípio em detrimento do outro em determinada situação funda-se na proporcionalidade que para Willis Santiago Guerra Filho teria contornos semelhantes à norma fundamental de Kelsen - e na razoabilidade de Siches.

O método de Luis Recaséns - método da lógica do razoável - está montado sobre o princípio aristotélico da equidade. Porém, para Recaséns, a função da equidade não é corrigir a lei, mas interpretá-la razoavelmente.

A lógica do razoável supera a pluralidade de métodos interpretativos, pois, em cada caso, o juiz deve interpretar a lei segundo o método que conduz a solução mais justa entre as possíveis. Não implica na substituição da lei por critérios subjetivos e pessoais do magistrado. Ele deve atender, na interpretação, à lei e demais critérios objetivos.

Possui como características, elencadas por Christiano José de Andrade ${ }^{25}$ :

$\left.1^{a}\right)$ está limitada pela realidade concreta do mundo em que opera. Encontra-se circunscrita pelo mundo social, tendo em vista o momento histórico da aplicação;

$2^{\mathrm{a}}$ ) funda-se em critérios axiológicos, alheios à dimensão da lógica formal, servindo de distinção entre o logos do razoável e o do racional;

$3^{a}$ ) a valoração é realizada tomando-se determinada situação humana real;

$4^{\mathrm{a}}$ ) o estabelecimento de propósitos e finalidades partem das valorações realizadas;

${ }^{23}$ CANOTILHO, José Joaquim Gomes e MOREIRA, Vital. Constituição da República Portuguesa Anotada. $3^{\text {a }}$ edição. Coimbra: Almedina.1993. p. 53.

${ }^{24}$ LARENZ, Karl. Derecho justo: fundamentos de ética jurídica. Traducción Luis Diez-Picazo. $1^{\mathrm{a}}$ edição. Madrid : Editorial Civitas S.A. 1985. p. 677.

${ }^{25}$ ANDRADE, Christiano José de. O Problema dos Métodos de Interpretação Jurídica - São Paulo: RT - 1992 - p. 84/85. 
$\left.5^{\mathrm{a}}\right)$ as finalidades e propósitos apoiam-se não apenas na valoração, mas são condicionados pelas possibilidades oferecidas pela realidade humana social concreta;

$6^{\mathrm{a}}$ ) em consequência,

a lógica do razoável é regida por razões de congruência ou adequação: 1) entre a realidade social e os valores (quais são os valores apropriados para a ordenação de uma determinada realidade social); 2) entre os valores e os fins (quais são os fins valiosos); 3) entre os fins e a realidade social concreta (quais são os fins de realização possível e razões para uma escala de prioridade entre eles); 4) entre os fins e os meios, quanto à conveniência dos meios para os fins; 5) entre os fins e os meios, relativamente à correção ética dos meios; e, 6) entre os fins e os meios no que se refere à eficácias dos meios $^{26}$.

Como visto, não se busca negar ou vedar a aplicação do princípio da soberania dos veredictos, mas aplicá-lo de forma mais equânime, no sentido descrito acima, dando a cada princípio o peso ou o valor para o caso concreto.

Poder-se-ia alegar que, nesse caso, restaria a ação revisional. Porém, o mesmo princípio que impediria a revisão da decisão do Tribunal do Júri impediria nova decisão.

\section{CONSIDERAÇÕES FINAIS}

Embora, como já manifestado acima, a soberania dos veredictos afasta do magistrado togado, seja de primeiro ou segundo grau, reanalisar a justiça da decisão - entendida como a opção por uma das interpretações possíveis - não pode afastar a reanálise nos casos teratológicos.

\footnotetext{
${ }^{26}$ SICHES, Luis Recaséns, “La Naturaleza Del Pensamiento Jurídico” - p. 461/462 apud ANDRADE Christiano José de, “O Problema dos Métodos ...” - ob. cit. - p. 84/85.
} 
Tanto assim que a própria lei deixa entrever que o julgamento não pode ser totalmente divorciado da prova dos autos, nos termos do artigo 593, III, $d$, do Código de Processo Penal.

Por tais motivos, para que não se solidifique uma injustiça - ser mantida uma decisão frontalmente contrária à prova dos autos, possível a reanálise.

Tal posição não afasta o princípio da soberania dos veredictos, mas o mitiga em uma aplicação conjunta com outros princípios como forma de garantia de Justiça material.

Entretanto, visto que a instituição do Júri foi criada para afastar o arbítrio, tal posicionamento, ser revista e alterada pelo Tribunal ad quem segunda decisão dos jurados, só pode ser aplicada em prol da defesa, como já ocorre nas revisionais.

Nesse caso, entretanto, o Tribunal ad quem não iria, novamente, anular o julgamento dos jurados, mas absolver diretamente o réu, para que não se eternizasse o julgamento.

\section{REFERÊNCIAS BIBLIOGRAFICAS}

ALEXY, Robert. Conceito e validade do Direito. São Paulo: WMF Martins Fontes Ltda. 2009.

ANDRADE, Christiano José de. Hermenêutica Jurídica no Brasil. São Paulo: Editora RT. 1991.

O Problema dos Métodos de Interpretação Jurídica. São Paulo: Editora RT. 1992.

BARBOSA, Rui. O Júri sob todos os aspectos. $1^{\text {a }}$ edição. Rio de Janeiro: Editora Nacional de Direito. 1950.

CANOTILHO, José Joaquim Gomes e MOREIRA, Vital. Constituição da República Portuguesa Anotada. $3^{\mathrm{a}}$ edição. Coimbra: Almedina.1993.

BONAVIDES, Paulo. Curso de Direito Constitucional. $6^{\text {a }}$ edição. São Paulo: Malheiros. 1996.

BULOS, Uadi Lammêgo. Constituição Federal Anotada. Editora Saraiva. $1^{\text {a }}$ edição. 2000.

GILISSEN, John. Introdução histórica do direito. $3^{\text {a }}$ edição. Lisboa: Fundação Calouste Gulbenkian. 2001. 
JESUS, Damásio Evangelista de. Código de Processo Penal Anotado. Editora Saraiva. $15^{\text {a }}$ edição. 1998.

LARENZ, Karl. Derecho justo: fundamentos de ética jurídica. Traducción Luis Diez-Picazo. $1^{\mathrm{a}}$ edição. Madrid : Editorial Civitas S.A. 1985.

_. Metodologia da Ciência do Direito. Trad. José Lamego. $3^{\text {a }}$ edição. Lisboa: Fundação Calouste Gulbenkian. 1997.

MIRABETE, Júlio Fabbrini. Processo Penal. Editora Atlás. 1ª edição. 1991.

NUCCI, Guilherme de Souza. Código de Processo Penal Comentado. 11 ${ }^{a}$ edição. São Paulo: Editora RT. 2012.

PORTO, Hermínio Alberto Marques. Júri: procedimento e aspectos do julgamento. Questionários. Editora RT. 5a edição. 1989.

ROCHA, Arthur Pinto da. O Júri e sua evolução. Rio de Janeiro: Leite Ribeiro \& Maurillo. 1919.

TOURINHO FILHO, Fernando da Costa. Processo Penal. Saraiva. 12 edição. 1990. 
